Boise State University

ScholarWorks

Organizational Performance and Workplace

Learning Faculty Publications and

Presentations

Department of Organizational Performance and

Workplace Learning

$5-2019$

\title{
A Needs Analysis to Inform Global Humanitarian Capacity Building
}

Jeroen Breman

Grid University

Lisa A. Giacumo

Boise State University

Rachel Griffith-Boyes

Totara Learning

This is a post-peer-review, pre-copyedit version of an article published in TechTrends. The final authenticated version is available online at doi: 10.1007/s11528-019-00390-6 
This is an author-produced, peer-reviewed version of this article. The final, definitive version of this document can be found online at TechTrends, published by Springer. Copyright restrictions may apply. doi: 10.1007/s11528-019-00390-6

\title{
A Needs Analysis to Inform Global Humanitarian Capacity Building
}

\author{
Jeroen Breman \\ Northwest Lineman College \\ Grid University \\ Meridian, ID, USA
}

\author{
Lisa A. Giacumo \\ Department of Organizational Performance and \\ Workplace Learning \\ Boise State University \\ Boise, ID, USA
}

\author{
Rachel Griffith-Boyes \\ Totara Learning \\ Brighton, UK
}

\begin{abstract}
This article describes a needs analysis case study to inform the instructional design of a multinational capacity building project in humanitarian logistics. Survey responses from 106 foreign partner non-governmental organizations (NGOs) of international non-governmental organizations (INGOs) were collected to gain insights into organizations' access to technology, levels of confidence in five logistics process areas, the strengths of previous capacity building projects, and organizational strategies and methods for capacity building. Results show that staff have access to mobile phones and computers and prefer to use the latter for learning. It was also found that not all NGOs implemented all the common logistics processes of an emergency response. Further, respondents preferred participatory approaches to scenario-based training over lecture-style presentations. Instructional design recommendations based on these results are shared as well as lessons learned which may help instructional designers working for multinational organizations design their needs analysis projects.
\end{abstract}

\section{Introduction}

Capacity building is a term that is often used in international development organizations. International development organizations adopt strategies to develop foreign organizations' independence and improve their performance. The United Nations Office for Disaster Risk Reduction (UNISDR, 2017) defines capacity building as

"the process by which people, organizations and society systematically stimulate and develop their capability over time to achieve social and economic goals” (para. 13).

This article discusses the results of a needs analysis case study that informed the instructional design of a capacity building project. This project was funded by a consortium of ten International Non-Governmental Organizations (INGOs) and the European Union Office for Civil Protection and Humanitarian Aid Operations (ECHO). While the results of this needs analysis case study are non-generalizable and may not be used to inform all INGO capacity building projects, they do illustrate some of the potential pitfalls and constraints instructional designers may encounter in cross-cultural and multinational work.

This case study originated from the desire of the instructional designers to inform the design and development of instructional and performance support materials that could be implemented in different organizations and delivered globally. Survey respondents answered a variety of both closed and open-ended questions. In the survey respondents were asked about: 1) experience with previous organizational capacity building projects, 2) organizational methods or strategies they used to build capacity, 3) their access to technology, and 4) their confidence levels with five logistics process areas (i.e., procurement, warehousing, distribution, fleet management and asset management). 
This is an author-produced, peer-reviewed version of this article. The final, definitive version of this document can be found online at TechTrends, published by Springer. Copyright restrictions may apply. doi: 10.1007/s11528-019-00390-6

\section{Background}

In 2015, a group of ten humanitarian INGOs collaborated to design and publish instructional training and performance support materials intended for INGOs to use when building the capacity of the supply and logistics staff in their foreign partner non-governmental organizations (NGOs) in countries where they operate. INGOs can be defined by their activities in developing countries to relieve suffering, relieve the effects of poverty, protect the environment, provide social services, or provide civil development (Werker \& Ahmed, 2008). The humanitarian sector is comprised of organizations which relieve the suffering of the most vulnerable people from natural causes or man-made emergencies, where governments are not able to or willing to provide aid to people in need. Humanitarian logistics is defined as "the process of planning, implementing and controlling the efficient, cost-effective flow and storage of goods and materials, as well as related information, from the point of origin to the point of consumption for the purpose of alleviating the suffering of vulnerable people” (Thomas \& Kopczak, 2005, p. 2).

The project stakeholders from the ten INGOs determined three main organizational challenges. Firstly, they found that their INGO staff were very unlikely to be the first on the ground when a humanitarian crisis emerged. Secondly, they described a high turnover rate across the local NGOs such that there was a constant need for training. Typically, new staff with low prior experience are hired to keep costs down when more experience staff leave positions. The new staff are generally eager for training. Thirdly, the stakeholders from the ten organizations in this consortium had historically taken a 'one-shot' approach to past training for staff of local NGOs, delivering lengthy classroom courses with little follow up in a central point in a region. There were limitations to the 'one-shot' approach, which included a lack of scalability. Further, high turnover of local NGO staff required frequent repetition of training resulting in extensive, costly travel.

The complete project scope for the instructional designers created a significant challenge; designing and developing instructional materials for a global audience, or at least for all those countries where humanitarian crises often happen. While the instructional design team had over 10 years of combined experience working with NGOs to design and deliver performance improvement solutions around the globe, they had not previously worked in many of the countries where this project was to be implemented. In addition, the work was to be implemented in multiple cultures and languages in order to support employees in separate, independent organizations, with their own unique structures and challenges.

\section{Problem Statement}

Project stakeholders within the INGOs had strong opinions regarding the correct approach. This included a bias towards classroom training, and assumptions made about likely resistance to this training within local NGOs due to concerns around staff retention. However, the high turnover rate in the local INGOs meant that the organizational needs and staff concerns change rapidly.

While some previous research shows training does not support retention in developing countries (Ahmad, \& Bakar, 2003; Teclemichael Tessema, \& Soeters, 2006), other researchers have suggested that staff development has been shown to increase retention (Ahsan, Fie, Foong, \& Alam, 2013; Al Momani, 2017; Manafa, McAuliffe, Maseko, Bowie, MacLachlan, \& Normand, 2009; Van Dormael, Dugas, Kone, Coulibaly, Sy, Marchal, \& Desplats, 2008). Therefore, the designers in this project didn't feel comfortable taking the stakeholders' assumptions into their design work; consequently, they decided to challenge them with a needs analysis exercise conducted via a survey.

Further, this project would require a substantial change from historically organizing training delivered directly to NGO staff located in a variety of countries in a few centralized places, such as the organization's headquarters. Instead, these materials would be designed to be implemented by INGO staff working in many different countries to train foreign partner NGO staff locally and around the globe, as recommended by Burde (2004) and Agg (2006). The designers needed to find out whether the foreign partner NGO staff would be willing and able to participate in training delivered in the classroom, or online, via mobile devices, or a blended approach. In addition, they needed to know whether the foreign partner NGO staff would need training and performance support across all logistics areas or to be able to choose a selection of modules to meet their organizations' specific needs (Okorley, \& Nkrumah, 2012). 
This is an author-produced, peer-reviewed version of this article. The final, definitive version of this document can be found online at TechTrends, published by Springer. Copyright restrictions may apply. doi: 10.1007/s11528-019-00390-6

\section{Significance of This Work}

Instructional designers can benefit from various examples of how to meet clients' needs (Howard, Boling, Rowland, \& Smith, 2012). The designers did not find any available publications with empirical evidence for the instructional and non-instructional interventions and technology choices (i.e. online learning, e-learning, and m-learning), which would be suitable for their context. According to Asino (2015), one should consider a comprehensive analysis of potential learners that includes lived experiences, attitudes, and perceptions, among other anthropological and psychological factors, when building learning applications. In addition, from our experience, gaining client approval to conduct a needs analysis is a persistent recurring problem that many practitioners face. Here, the designers provide up-to-date evidence that other designers can use and share with clients to justify exploration into potential design approaches and delivery modalities appropriate for audiences located in dispersed cultures.

\section{Theoretical Framework}

Due to the scope of this project, the Van Tiem, Moseley, and Dessinger (2012) Human Performance Technology Model was used. Specifically, this article focuses on the needs analysis technique of a full performance analysis (i.e., extant data analysis, needs analysis, knowledge task analysis, procedural task analysis, and systems task analysis) (Van Tiem, Moseley, \& Dessinger, 2005). Also, Gilbert's (1978) Behavioral Engineering Model was drawn upon. These models were chosen because they have been shown to guide practitioners' work on improving organizational performance and workplace learning needs (Stolovitch \& Keeps, 2006). Workplace learning was defined as the "acquisition of knowledge or skills by formal or informal means that occur in the workplace" (Cacciattolo, 2015).

The elements from Young's (2008) Culture Based Model (CBM) were applied to the needs analysis. This model was selected because of our global target audience and because it aids "the designer or researcher in better understanding the intricacies of a society, culture, or target audience" (Young, 2008). Also, the CBM guides both project management and design, with a call for at least one community representative on the team who "knows the culture of the target audience and is involved in all aspects of the design” (Young, 2008).

\section{Needs Analysis}

A needs analysis is essential to understand what would need to happen to make a sector-wide humanitarian supply and logistics capacity development project successful (Van Tiem, Moseley, \& Dessinger, 2012). Therefore, the instructional design team solicited the consortium members' input on "what should be happening, what is happening, how the sources feel about what is or is not happening, and what is causing the problem" (Van Tiem, Moseley, \& Dessinger, 2005). The consortium included at least one community representative for each geographic location to provide input on our performance analysis work (Young, 2008). The instructional designers also asked the consortium members about the environment, including locations of the partner NGOs and their stakeholders, the organizational information systems, resources, incentives, individuals' motives, capacity, knowledge, and skills (Gilbert, 1978). Multiple data sources were used to verify information gathered from the consortium by asking the local NGO managers and staff about the organizational expectations, resources for work, incentives, as well as their motives, capacity, knowledge, and skills (Gilbert, 1978). A breakdown of the areas of the needs analysis inquiry, aligned with the Behavioral Engineering Model and their significance, is presented next (Gilbert, 1978).

\section{Organizational Incentives and Individuals' Motives and Expectations}

Based on the conflicting evidence previously described, the designers wanted to know whether training would help retain local NGO staff. They planned to ask whether respondents agreed with the following statement: Training and capacity building leads to greater retention of staff. The statement was deliberately positively framed, to avoid confirmation bias.

Also, a series of questions designed to assess the motivation of learners to take part in capacity building activities, and their expectations and preferences around methods of training delivery were planned. The team intended to ascertain potential learners' ability and willingness to spend time on different training intervention types, both instructional and non-instructional. This included both online and offline, synchronous and asynchronous activities because of the access rates to computers and internet in developing nations (Rao, 2005). Also, the willingness and ability of potential 
This is an author-produced, peer-reviewed version of this article. The final, definitive version of this document can be found online at TechTrends, published by Springer. Copyright restrictions may apply. doi: 10.1007/s11528-019-00390-6

learners to participate in instructional interventions that were delivered in face-to-face training, e-learning, online learning, or blended learning environments was explored. For example, respondents were asked to rate different types of interventions they would be willing to engage with.

\section{Organizational Resources and Individuals' Capacity}

To understand the environment, a series of questions about the organizational resources and potential learners' ability to use four types of technology tools; internet-connected computer, CD-ROM, mobile text messages and internetconnected smart phones were planned. While historically Mercer (2004) states "a minority of well-resourced, urban and/or international NGOs have access to ICT facilities” (p 49), individuals' access to internet-connected mobile phones have dramatically increased in developing nations (Gitau, Marsden, \& Donner, 2010). One of the project goals was to help move outcomes from individual performance to organizational performance. Therefore, a key to the success of this project would be the willingness and ability of learners to share information with others in their organization. Hence, the instructional designers wanted to know whether respondents currently shared information with others; and if they share online, where and how they share it because many websites are not mobile-friendly (Gitau, Marsden, \& Donner, 2010). A community representative from each local NGO informed us of participants' language proficiency.

\section{Organizational Information Systems and Individuals' Knowledge or Skill Sets}

To understand expectations, the instructional designers planned to explore past experiences of capacity building and how effective they were according to the respondents. Open-ended questions with a free-text response could be used to acquire qualitative data and not restrain the responses. Further, the designers planned to gather information about the logistics knowledge and skills that were expected of the employees from each organization. The designers also planned to explore how confident the respondents were in their employees' ability to demonstrate the expected logistics knowledge and skills. Future humanitarian crises may result in the need for organizations to grow capacity in other supply and logistics areas, too. Therefore, the team also planned to inquire about respondents' confidence in all logistics areas, even if they had indicated that their organization did not currently perform all activities. This information would help decide if materials would need customizations for individual local NGO needs (Okorley \& Nkrumah, 2012).

\section{Research Questions and Methods}

The purpose of this needs analysis was to gather the opinions and ideas from the INGO and NGO stakeholders, managers, and performers (Van Tiem, Moseley, \& Dessinger, 2005). The instructional designers sought to gather their input on the incentives, motives, expectations, resources, capacity, information, knowledge, and skills, (Gilbert, 1978) relevant to humanitarian organizations' supply and logistics capacity building needs. Therefore, they sought to answer the following research questions in partnership with our stakeholders:

1. What are the performance improvement sector-wide NGO humanitarian supply and logistics capacity development needs?

2. What performance improvement interventions would best support a sector-wide NGO humanitarian supply and logistics capacity development initiative?

Given the global nature of this project, an online survey was chosen in order to quickly reach a large group of local NGOs. These local NGOs generally communicate with their INGO counterparts through email and have access to at least one internet-connected computer.

Survey questions were first developed by the instructional designer with input from the project team and management. Then, the project's steering committee members, comprised of five of the 10 consortium member organizations, provided feedback to refine and to establish the content validity of the survey. The individuals on the steering committee had over 50 years of combined experience living and working in a wide variety of countries representative of the target audience for the survey and served as community representatives (Young, 2008). 
This is an author-produced, peer-reviewed version of this article. The final, definitive version of this document can be found online at TechTrends, published by Springer. Copyright restrictions may apply. doi: 10.1007/s11528-019-00390-6

The survey consisted of 55 questions covering nine areas (see Appendix A). Not all questions would be seen by all respondents. Some depended on answers to earlier questions. The survey consisted of five types of questions: dropdown lists, multiple-choice, Likert-scale, checkboxes, and free text. Select questions were mandatory while others were optional. The survey was created in an online tool called SurveyGizmo (https://www.surveygizmo.com/). Examples of questions are included in Appendix A.

The selection criteria for participation in this needs analysis case study included current staff working in foreign partner NGOs of the previously described humanitarian INGOs. Six members of the INGO consortium provided last known email addresses. Survey recruitment email messages were sent to a total of 190 addresses, each located at a different NGO. Of those, 146 were successfully delivered; 44 emails bounced back as undeliverable. The email message and the survey were available in three languages: French, Portuguese, and English. After two weeks a reminder was sent to those who had not filled out the survey and those who only partially filled it out. The survey response collection was closed after four weeks.

In total, 106 individuals responded, originating in 15 countries in Asia, Africa, and Latin America. There were 38 complete surveys and 68 partial surveys. The most responses to a single question in the survey was 72 . With $73 \%$ of the individuals successfully contacted by email responding at least in part to the survey, and over a quarter completing the full survey, the response exceeded expectations.

Quantitative data were taken directly from the report that SurveyGizmo produces. The instructional designer summarized the open question responses and presented the patterns which arose to the project's steering committee. The project's steering committee, which consisted of five community representatives who were familiar with the culture of the target participants, helped make meaning of the responses and then advised future design decisions (Young, 2008).

\section{Results and Discussions}

\section{Access to Technology}

The survey included a series of questions about access to four types of technology. These included CD-ROM, internetconnected computer, mobile text messages and internet-connected smart phones. Participants were asked whether they had access to and whether they would be willing to use the technology for learning. Results are summarized in Table 1 .

Table 1

Access to technology and willingness to use these for training.

\begin{tabular}{|c|c|c|c|c|c|c|}
\hline & \multicolumn{2}{|c|}{ Access? } & \multicolumn{3}{|c|}{ Willing to use? } & \\
\hline & $\underline{\text { Yes }}$ & $\underline{\text { No }}$ & $\underline{\text { Yes }}$ & No & $\underline{N} / \mathrm{A}^{\mathrm{a}}$ & $\underline{\mathrm{n}}$ \\
\hline Computer with CD-ROM & $\overline{41}$ & $\overline{2}$ & $\overline{39}$ & $\overline{0}$ & $\overline{4}$ & $\overline{43}$ \\
\hline Computer with Internet & 41 & 2 & 40 & 1 & 2 & 43 \\
\hline Mobile phone with SMS & 41 & 0 & 32 & 6 & 3 & 41 \\
\hline Internet-connected smartphone & 28 & 13 & 30 & 5 & 6 & 41 \\
\hline
\end{tabular}

${ }^{a}$ Option included due to nuance of survey authoring tool and being unable to only specify this questions for respondents who had previously answered yes.

The highest level of access was via text messages on a mobile phone, with 100\% of respondents indicating that they have access to a mobile phone which can send/receive texts. This was followed by computers with CD-ROM and internet access; each scoring 95\%. Only 78\% of respondents indicated they would be willing to use text messages for learning. This was considerably lower than the willingness to use CD-ROM and computer-based internet for learning.

Responses to questions on standard and smart mobile phones elicited a number of comments about sharing information with peers. A theme emerged, suggesting that these tools naturally lend themselves to peer learning networks, perhaps more readily than a computer. The following responses evidence this theme:

"Major conversation done through SMS or calls. But SMS or Calls is a secondary source of information." 
This is an author-produced, peer-reviewed version of this article. The final, definitive version of this document can be found online at TechTrends, published by Springer. Copyright restrictions may apply. doi: 10.1007/s11528-019-00390-6

"Usamos FrontlineSMS para difusao de informacoes dentro da Organização." ("We use FrontlineSMS [a group SMS delivery tool] to share information within the organization”).

“25\% staff have smart phone.”

"Limited to Senior management members."

"Use normal phones due to low salary packages."

\section{Time Devoted to Training}

The question about how much time they might be willing to devote to training in a six-month capacity building program was answered by 40 respondents (see Figure 1.) The most common response was more than four hours a week (i.e., 16 responses). Nine and eight respondents chose four and two hours per week respectively. One hour was selected three times and 30 minute or 'no time for training' each had two respondents. Comments revealed rationale for selections and included:

"Depending on the intensity of training, we would consider extending number of hours per week, particularly if these are flexibly spread along the week to allow staff time to devote to other tasks.”

"Je suis personnellement trop pris par le management des mes équipe et de mon administration.” ("I personally am too busy with the management of my time and my administration.”)

\section{More than 4 hours per week}

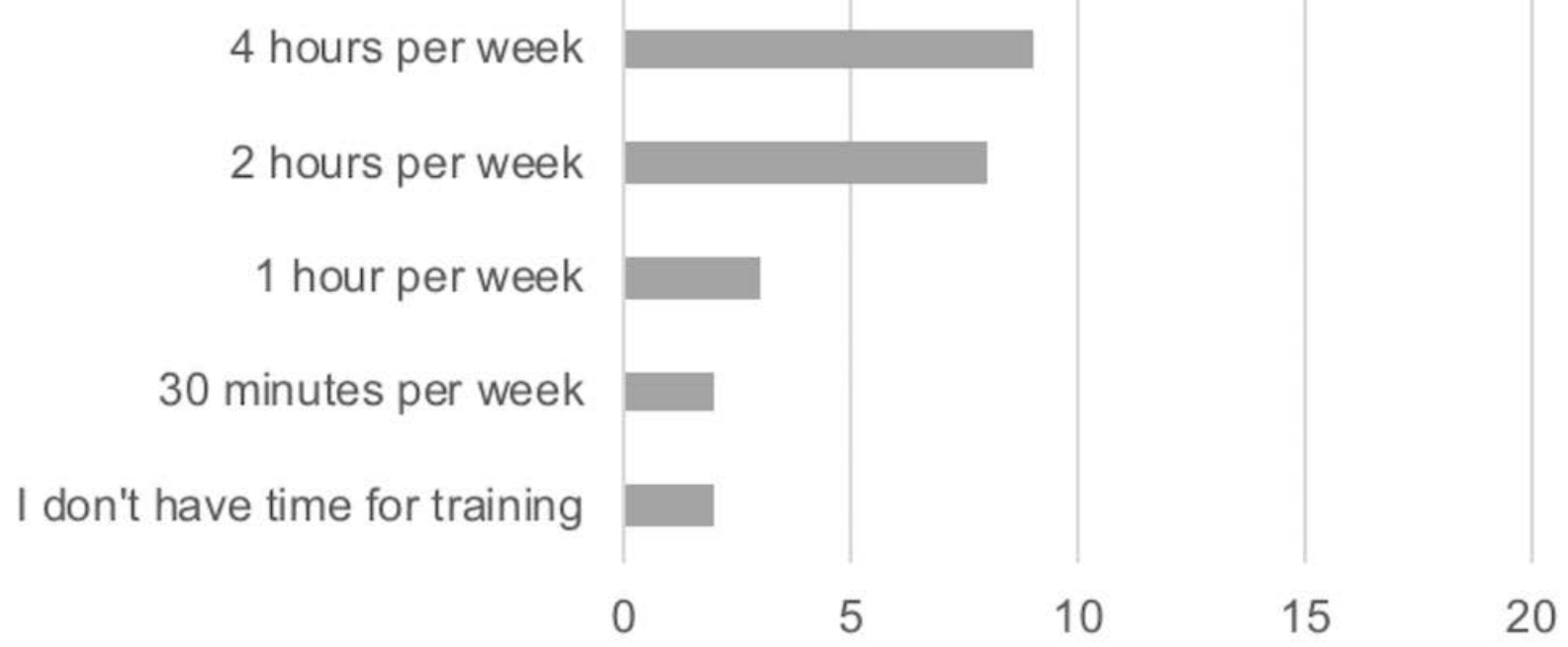

Figure 1. Time allocated for training in a six-month capacity building program $(\mathrm{n}=40)$.

\section{Information Sharing}

Respondents were asked to think about how they sought and shared information about logistics in their organization. The most popular source was manuals, followed closely by colleagues within their organization. Contributing to an online blog or community was selected by $45 \%$ of respondents, with almost $95 \%$ doing so to share their knowledge. Of those who contributed to a blog, $58 \%$ had also used it to seek answers to questions, suggesting a reciprocal relationship with a bias towards sharing expertise. 
This is an author-produced, peer-reviewed version of this article. The final, definitive version of this document can be found online at TechTrends, published by Springer. Copyright restrictions may apply. doi: 10.1007/s11528-019-00390-6

\section{Logistics Processes}

The designers asked respondents what particular logistics processes their organization would be involved with. Also, respondents were asked to rate their organizations' strength in these processes. Further, designers asked how confident they felt about their organization being able to manage the processes in five areas of logistics--procurement, warehousing, fleet, distribution, and assets-if a humanitarian emergency would happen tomorrow.

Logistics Areas. The survey responses showed that not all foreign partner organizations implement all the common logistics processes of an emergency response. Of the sixty-one respondents to this question, most (i.e., 61) were involved in procurement, 45 in warehousing, 53 in fleet management, 60 in distribution. The least (i.e., 47) were involved with asset management.

Strength of Processes and Applications in an Emergency Response. Table 2 shows how different partners rated the strength of logistics processes in their organization. It also shows the confidence they have in the management of these processes in their organization if an emergency happened tomorrow. Partners felt strongest in distribution, procurement, and fleet management and weaker in warehousing and asset management. A similar division was found in their confidence to manage those logistics processes in an emergency.

Table 2

Strength of logistics process and confidence to manage them in an emergency.

\begin{tabular}{|c|c|c|c|c|c|c|}
\hline \multicolumn{7}{|c|}{ Rating of strength of organization's logistics processes } \\
\hline & very weak & weak & average & $\underline{\text { strong }}$ & very strong & $\underline{\mathrm{n}}$ \\
\hline Procurement & 0 & $\overline{3}$ & 16 & 31 & 5 & $\overline{55}$ \\
\hline Warehousing & 4 & 2 & 16 & 12 & 3 & 37 \\
\hline Fleet management & 1 & 5 & 19 & 19 & 7 & 51 \\
\hline Distribution & 0 & 2 & 9 & 19 & 17 & 47 \\
\hline Asset management & 0 & 3 & 16 & 9 & 5 & 33 \\
\hline \multicolumn{7}{|c|}{ Rating of confidence to manage logistics processes in emergency } \\
\hline & very low & low & average & high & very high & $\underline{\mathrm{n}}$ \\
\hline Procurement & 1 & 6 & 19 & 27 & 5 & 58 \\
\hline Warehousing & 0 & 11 & 20 & 19 & 2 & 52 \\
\hline Fleet management & 3 & 9 & 12 & 22 & 4 & 50 \\
\hline Distribution & 0 & 3 & 10 & 26 & 10 & 49 \\
\hline Asset management & 1 & 7 & 17 & 18 & 4 & 47 \\
\hline
\end{tabular}

Previous Capacity Building Projects

Respondents were asked to think about past capacity building projects and explain the most and least useful strategies and methods, and why. They were also asked if capacity building influenced retention of staff. The results are described next.

Most Useful Strategies and Methods. Many respondents focused on naming particular training interventions rather than focusing on why they were the most useful. Responses which did focus on strategies and methods included: 1) good stakeholder involvement, 2) sharing experiences, 3) participatory diagnosis of strength and weaknesses, and 4) training based on real work an organization is doing. For example, one responded answered:

"The most useful training and capacity building we had were those that took into consideration our own reality and built from there. On-the-job training and coaching revealed most successful and useful as we could relate with our own day to day reality."

Least Useful Strategies and Methods. This question elicited a lot of interesting responses around appropriateness of training, although many respondents claimed that they had never participated in poor capacity building. Comments included: 1) training topic minimally relevant for the area, 2) inability to equip staff with the materials to apply the training, 3) limited field experience of trainers, and 4) lack of funding to fully adopt the trained system. The least useful training methods mentioned included lectures, in particular those involving a lot of PowerPoint. 
This is an author-produced, peer-reviewed version of this article. The final, definitive version of this document can be found online at TechTrends, published by Springer. Copyright restrictions may apply. doi: 10.1007/s11528-019-00390-6

Capacity Building and Staff Retention. When asked if training and capacity building led to greater retention of staff $(\mathrm{n}=45), 71$ percent of respondents agreed, 18 percent neither agreed nor disagreed, and 11 percent disagreed. Respondents who felt that capacity building led to greater retention of staff commented for example:

"La formation améliore la compétence et développe l'esprit d'initiative et d'innovation” ("Training improves skills and develops a spirit of initiative and innovation.”)

"Staff does not always look for salaries and benefits they also look for professional growth.”

Respondents who felt that capacity building decreased staff retention did so because:

"Usually trained staff searches better opportunity in other organizations."

\section{Features of Capacity Building Interventions}

The instructional designers asked a series of questions about features of a possible capacity building intervention to assess preferences. These questions focused on time allocated and different delivery methods and approaches. The results are described next.

Capacity Building Activities. "Which activities would you be willing to do as part of a capacity building training course?” was answered by 40 respondents. They were asked to 'check all that apply.' Results are given in Table 3. Respondents were most interested in visiting another organization, followed by taking part in face-to-face meetings and preparing presentations to deliver in advance of a training. Respondents were less willing to host another organization. Online learning and regular phone calls had the least appeal for the respondents.

Table 3

Willingness to participate in different capacity building activities.

\begin{tabular}{ll}
\hline Take an online module (e-learning) in advance & 26 \\
Prepare a presentation in advance and deliver it in the training & 32 \\
Visit another organization to observe their ways of working & 33 \\
Host a visitor from another organization to share your ways of working & 28 \\
Take part in regular phone calls & 17 \\
Take part in regular face-to-face meetings & 32 \\
\hline
\end{tabular}

Delivery Preference. Forty individuals responded to the question about their preference for online, or face-to-face training, or a combination of the two. Of all respondents, 27 chose the combination of online and face-to-face training. Eleven preferred face-to-face training and only two choose online training. Some partners commented:

"Face to face session is more convenient for direct participation, sharing issues and learning. Online training is also important for referral services of information."

"Ça permet au personnel de rester au lieu du travail et suivre la formation et réduire les coût de formation" ("It [online training] allows staff to stay at the workplace and follow the training and reduce costs.")

"Training should to be face to face otherwise it would not lively."

\section{Discussion and Implications for Instructional Designers}

In this section, implications of the survey results will be discussed and presented. Findings suggest that foreign partner organizations are aware of their capacity building strengths and need for further support. First the supply and logistics needs are discussed followed by the performance improvement interventions. Recommendations for the design of the training materials and performance support systems are included. 
This is an author-produced, peer-reviewed version of this article. The final, definitive version of this document can be found online at TechTrends, published by Springer. Copyright restrictions may apply. doi: 10.1007/s11528-019-00390-6

\section{Supply and Logistics Capacity Development Needs}

Logistics areas. Results show that not all foreign partner organizations implement all the common logistics processes. A number of respondents commented on the importance of tailoring training to the context and organizational need, considering where the organization is today and basing training on that assessment. The designers recommended that capacity building should be tailored to the organization and context, based on needs identified through assessment. Training should be developed in a modular way, so that training could be organized for only those topics that a partner or group of partners need. Also, training should be scenario-based so that training could be adapted to realistic local scenarios.

Technical Expertise and Confidence. INGOs work with foreign partner NGOs for different reasons; including their knowledge of the region and markets where work needs to be done and their contacts in the local communities. This is reflected in the results which show that processes in buying and distributing goods are rated as strong and confidence is high in the organizations' ability to manage such processes were a disaster to happen tomorrow. Respondents reported that their organizations engaged in the other areas of supply and logistics less often and reported that their confidence was low in the organizations' ability to manage such processes were a disaster to happen tomorrow.

The designers recommended that emphasis in partner capacity building be placed dependent on the confidence reported within each select logistics area. For example, respondents scored distribution highly in both strength of process and confidence to respond, whereas warehousing scored significantly lower in both measures. Thus, more time should be spent on warehousing. Also, a modular design would allow INGOs to offer only those topics where partners assess themselves as weaker.

\section{Performance Improvement Interventions}

Capacity Building Experiences. Multiple respondents reported training delivery by 'lecture' as the least useful approach. Respondents also reported that training based on the real work organizations were doing was useful; theoretical training was not. Thus, designers recommended that training be practical, active, and scenario-based, rather than theoretical. Any lecture-style delivery should be kept to a minimum.

Capacity Building Features. Respondents reported their willingness to dedicate a large amount of time to training. Most respondents reported their willingness to spend two to four hours a week, provided time could be spent flexibly around job demands. The designers therefore recommended that training should be modularized and asynchronous where possible, to allow learners to organize their time spent on training around other responsibilities.

Combining a number of different training approaches was overwhelmingly popular. Most popular was visiting another organization to observe their ways of working. However, hosting a visitor from another organization was the second least popular activity. Regular face-to-face meetings was almost twice as popular than regular phone calls. Respondents felt that a combination of face-to-face and online training would work best for their organization, although a number of comments indicated that online training was seen more as a support or reference tool than the 'gold standard' of face-to-face.

The designers therefore recommended a combination of a number of approaches. These include an assessment, online and face-to-face training elements, an ongoing coaching relationship between the INGOs and their foreign partner NGOs, and building networks between partner NGOs. Finally, capacity building should facilitate exchange visits between partner organizations to share knowledge and processes.

Use of Technology. The results of the survey show that access to technology was high, with the highest access for mobile phones and text messages. Most preferred use of computers over phones. The cost of pay-per-use contracts on personal mobile phones may play a role here. Low levels of access were reported for internet-connected smart phones. Whatever the technology, a number of respondents saw technology as a supporter rather than a replacement for other forms of training.

The designers recommended that technology not be used as the sole method of delivery. Contrary to the often-held assumption, access to an internet-connected computer was high. Thus, designers suggested to include internet-based learning. 
This is an author-produced, peer-reviewed version of this article. The final, definitive version of this document can be found online at TechTrends, published by Springer. Copyright restrictions may apply. doi: 10.1007/s11528-019-00390-6

\section{$\underline{\text { Limitations }}$}

There were some limitations to this case study. First, only surveys were used. Invitations were sent using email and the survey needed to be completed online, which would exclude those without access to the internet. However, sometimes NGO staff go to their INGO partner's office to access email and the internet. The designers did not attempt to gather data from local NGOs that did not use email to communicate. Also, time and cost constraints kept the designers from interviewing respondents.

Also, the needs analysis was part of a multinational capacity building project. The instructional designers included the recommended cross-cultural community representatives in the needs analysis design and project management activities as recommended by Young (2008). Feedback was received from people with knowledge of and work experience in countries from the target audience. However, representation from the target audience itself in the design of the survey and response analysis would be optimal.

The survey tool used did not allow comparison by geographic area or country. It would be recommended the use of a survey tool which would allow for parsing of data according to select subgroups to account for regional differences. Further, managers and staff member responses were not separated into two distinct groups for comparison. The separation was avoided because individuals often perform multiple roles in small organizations, which would have also made separation and comparison flawed. And, data were analyzed by only one person only. Personal bias could affect their choices in summarizing the results for the steering committee.

\section{Conclusion}

This needs analysis case study set out to test assumptions about the strategies and methods for an initiative by ten INGOs to build the capacity of their foreign partner NGOs on the topic of humanitarian logistics. Response rates were adequate. The authors suggest future needs analysis project plans to include a planned strategy to follow up with nonresponders if a higher response rate is required.

The results of this case study show that instructional designers of multinational work should not omit the needs analysis. In this case, several preconceptions of those involved in the project did not match the results of the needs analysis. For example, employee retention was not seen as a barrier to offering additional training in most foreign partner organizations, and access to computers with internet was high. The needs analysis results allowed us to recommend a more diverse capacity building strategy, including the desired tailoring to organizations and contexts, based on needs identified through systematic and systemic analysis. Instructional designers could use this case as evidence to support future project needs as well as to justify future needs analysis investigations.

\section{Compliance with Ethical Standards}

\section{Funding}

This project was funded by a consortium of ten INGOs and the European Union office for civil protection and humanitarian aid operations (ECHO). The consortium members were: Concern Worldwide, MercyCorps US, Save the Children International, Tearfund, World Vision International, and five Oxfam affiliates-Oxfam Great Britain, Oxfam Novib, Intermon Oxfam, Oxfam US, and Oxfam Australia. 
This is an author-produced, peer-reviewed version of this article. The final, definitive version of this document can be found online at TechTrends, published by Springer. Copyright restrictions may apply. doi: 10.1007/s11528-019-00390-6

\section{References}

Agg, C. (2006). Trends in Government Support for Non-Governmental Organizations. Golden age” of the NGO Behind Us. Geneva, Switzerland: United Nations Research Institute for Social Development.

Ahmad, K. Z., \& Bakar, R. A. (2003). The association between training and organizational commitment among white-collar workers in Malaysia. International journal of training and development, 7(3), 166-185.

Ahsan, N., Fie, D. Y. G., Foong, Y. P., \& Alam, S. S. (2013). Relationship between retention factors and affective organisational commitment among knowledge workers in Malaysia. Journal of Business Economics and Management, 14(5), 903-922.

Al Momani, M. (2017). Factors influencing public hospital nurses' intentions to leave their current employment in Jordan. International Journal of Community Medicine and Public Health, 4(6), 1847-1853.

Asino, T. I. (2015). The Future of our field. TechTrends, 59(1), 20-30.

Burde, D. (2004). International NGOs and best practices: The art of educational lending. In G. Steiner-Khamsi (Ed.), The global politics of educational borrowing and lending, (pp. 173-187). New York: Teachers College Press.

Cacciattolo, K. (2015). Defining workplace learning. European Scientific Journal, (February Special Edition)1, 243-250.

Gilbert, T. F. (1978). Human competence: Engineering worthy performance. New York: McGraw-Hill.

Gitau, S., Marsden, G., \& Donner, J. (2010, April). After access: challenges facing mobile-only internet users in the developing world. In, Proceedings of the SIGCHI Conference on Human Factors in Computing Systems (pp. 2603-2606). New York: ACM.

Howard, C. D., Boling, E., Rowland, G., \& Smith, K. M. (2012). Instructional design cases and why we need them. Educational Technology, 52(3), 34-38.

Manafa, O., McAuliffe, E., Maseko, F., Bowie, C., MacLachlan, M., \& Normand, C. (2009). Retention of health workers in Malawi: perspectives of health workers and district management. Human resources for health, $7(1), 65$.

Mercer, C. (2004). Engineering civil society: ICT in Tanzania. Review of African Political Economy, 31(99), 49-64.

Okorley, E. L., \& Nkrumah, E. E. (2012). Organisational factors influencing sustainability of local nongovernmental organisations: Lessons from a Ghanaian context. International Journal of Social Economics, 39(5), 330-341.

Rao, S. S. (2005). Bridging digital divide: Efforts in India. Telematics and informatics, 22(4), 361-375.

Stolovitch, H. D., \& Keeps, E. J. (2006). Handbook of human performance technology: Principles, practices, and potential. San Francisco, CA: John Wiley \& Sons.

Teclemichael Tessema, M., \& Soeters, J. L. (2006). Challenges and prospects of HRM in developing countries: testing the HRM-performance link in the Eritrean civil service. The international journal of human resource management, 17(1), 86-105.

Thomas, A. S. \& Kopczak, L. R. (2005). From logistics to supply chain management: The Path forward in the humanitarian sector. [White paper]. San Francisco, CA: Fritz Institute. Retrieved July 2, 2017, from http://www.fritzinstitute.org/pdfs/whitepaper/fromlogisticsto.pdf

UNISDR. (2017). Terminology. Retrieved from https://www.unisdr.org/we/inform/terminology

Van Dormael, M., Dugas, S., Kone, Y., Coulibaly, S., Sy, M., Marchal, B., \& Desplats, D. (2008). Appropriate training and retention of community doctors in rural areas: a case study from Mali. Human Resources for Health, 6(1), 25.

Van Tiem, D., Moseley, J. L., \& Dessinger, J. C. (2005). Fundamentals of performance improvement: Optimizing results through people, process, and organizations (2nd ed.). San Francisco, CA: John Wiley \& Sons.

Van Tiem, D., Moseley, J. L., \& Dessinger, J. C. (2012). Fundamentals of performance improvement: Optimizing results through people, process, and organizations (3rd ed.). San Francisco, CA: John Wiley \& Sons.

Werker, E., \& Ahmed, F. Z. (2008). What do nongovernmental organizations do? Journal of Economic Perspectives, 22(2), 73-92.

Young, P. A. (2008). The Culture based model: Constructing a model of culture. Educational Technology \& Society, 11(2), 107-118. 
This is an author-produced, peer-reviewed version of this article. The final, definitive version of this document can be found online at TechTrends, published by Springer. Copyright restrictions may apply. doi: 10.1007/s11528-019-00390-6

Appendices

Appendix A. Nine areas of questions in the surveys, including examples.

\section{About you}

Questions about the respondent.

What country is your organization based in?

\section{Your organization}

Questions about the activities the respondent's organization undertakes (under the five process areas) and their confidence in their ability to do so.

Imagine a humanitarian emergency happens tomorrow in your area. How confident are you that your organization could manage the procurement/ warehousing/fleet/ distribution/ assets needed?

\section{Experience with capacity building}

Questions about positive and negative experiences with capacity building, effect on staff retention and organizational knowledge sharing.

Think about training and capacity building your organization has experienced in the past. What was the most useful and why?

\section{Computer use}

Questions about access to computers with CD-ROM and internet access and willingness to use them for training.

Do staff in your organization have access to an internet-connected computer (a computer which allows you to view websites and browse the internet)?

\section{Mobile use}

Questions about access to mobile devices with text-message and internet capability and willingness to use them for training.

Some capacity building uses text messages for training. If you have access to a mobile phone which can send/receive text messages, would you and your colleagues use it for learning?

\section{Delivery methods}

Questions relating to possible delivery methods for capacity building and willingness to participate. Imagine you are on a training programme that lasts for six months. How many hours a week would you be willing to spend on training (such as taking e-learning courses, phone calls, visits to other organisations)?

\section{Sources of information}

Questions about where respondents look for information, focusing on participation in online knowledge sharing.

Imagine you have a logistics task to complete and you don't know how to do it. Where do you go for information?

\section{Advice}

A single question asking for any other information that may help us improve capacity building.

The project team is trying to make capacity building better. What else can you tell us that might help us to do so?

\section{Keep in touch}

Questions about whether we can contact respondents in future and opt-in to project communications.

Would you be willing to participate in a short interview, if we had any further questions? 